\title{
Occurrence of Ceramide Aminoethylphosphonate in Edible Shellfish, AGEMAKI, Sinonovacula constricta ${ }^{\dagger}$
}

\author{
Masato TAMARI and Makoto KANDATSU* \\ Laboratory of Food and Nutrition, Faculty of Education, \\ Nagasaki University, Nagasaki 852, Japan \\ *Department of Agricultural Chemistry, Faculty of Agriculture, \\ The University of Tokyo, Bunkyo-ku, Tokyo 113, Japan
}

Received November 25, 1985

\begin{abstract}
Ceramide aminoethylphosphonate was isolated from the shellfish, AGEMAKI, Sinonovacula constricta. The compound was purified through a combination of mild alkaline hydrolysis of the total lipids, QAE-Sephadex-A25 column chromatography and two dimensional thin layer chromatography. The infrared spectrum showed an absorption band at $1180 \mathrm{~cm}^{-1}$ due to a C-P bond, and was essentially identical with that of the standard ceramide aminoethylphosphonate. Upon hydrolysis of the substance with a strong acid, neither a change in its chromatographic behavior nor liberation of inorganic phosphate was observed. The stability of the compound as to acid hydrolysis suggested the presence of a C-P bond. On comparison with the synthetic compound, the aqueous hydrolysis product was found to behave like 2-aminoethylphosphonic acid on thin layer chromatography.

The predominant fatty acids were palmitic acid and stearic acid. The results obtained suggest that a person may ingest and absorb 2-aminoethylphosphonic acid, through the food chain, on the consumption of edible shellfish.
\end{abstract}

A natural compound containing a carbonphosphorus bond was first detected when Horiguchi and Kandatsu ${ }^{1)}$ isolated 2-aminoethylphosphonic acid (ciliatine) from acid hydrolysates of a proteolipid-like substance prepared from ciliate protozoa in the sheep rumen. Subsequently, this compound has been shown to be present either in a free form or bound to proteins or lipids in the prtozoan, Tetrahymena pyriformis, fresh water molluscs, terrestrial mammals, and marine animals in the following phyla, coelenterata, Mollusca and Echinodermata.

The distribution of the compound was reviewed by Quin, ${ }^{2)}$ and notable additional marine sources were reported by Hori et al. ${ }^{3)}$ Since the isolation of 2-aminoethylphosphonic acid, thirteen other aminophosphonic acids, structurally related to 2-aminoethylphospho- nic acid, have been discovered in biological materials. ${ }^{4)}$

The known N-methyl derivatives containing a carbon-phosphorus bond are $\gamma$-amino$\beta$-phosphonopropionic acid, isolated by Kittredge and Hughes $^{5}$ from Zoanthus sociatus, and $\mathrm{N}$-methyl, $\mathrm{N}, \mathrm{N}$-dimethyl and $N, N, N$-trimethyl aminoethylphosphonic acids, isolated by Kittredge et al. ${ }^{6}$ from Anthopleura. xanthogrammica.

So far, nine phosphonate-containing lipids (termed phosphonolipids ${ }^{7)}$ ) have been found as analogs of phosphatidylethanolamine, phosphatidylcholine and sphingoethanolamine in tissues of lower ${ }^{8)}$ and higher animals. ${ }^{9)}$

In addition, much information on the metabolism in lower and higher animals has been reported. ${ }^{4,10)}$

$\dagger$ This report was presented at the Annual Meeting of the Agricultural Chemistry Society of Japan, held in Tokyo, April 3, 1984. 
Rouser $e{ }^{a l} .{ }^{11)}$ first isolated a characteristic lipid from a sea anemone by means of column chromatography, and it was assumed tentatively to consist of a ceramide attached to 2aminoethylphosphonic acid by an ester linkage. Subsequently, this ceramide 2-aminoethylphosphonate has been shown to be widely present in both freshwater and sea water shellfish, ${ }^{12)}$ and in fungi. ${ }^{13)}$.

Recently, increasing attention has been paid to fish and shellfish as natural resources.

Therefore, our interest in the mammalian metabolism of aminophosphonic acids has led to the present investigation on the detection and isolation of the ceramide aminoethylphosphonate in an edible shellfish, AGEMAKI, Sinonovacula constricta.

\section{MATERIALS AND METHODS}

Materials. QAE-Sephadex-A25 was a product of Pharmacia. AGEMAKI, Sinonovacula constricta, was purchased on the local market.

Monomethylaminoethylphosphonic acid was purchased from Calbiochem, Los Angeles.

Fractionation of phosphorus fractions in AGEMAKI. ${ }^{14)}$ The freeze-dried material $(1.56 \mathrm{~g})$ of Sinonovacula constricta was extracted twice with $30 \mathrm{ml}$ of acetone by an efficient magnetic stirrer in a $100 \mathrm{ml}$ beaker at room temperature. The acetone extracts were centrifuged at $3000 \mathrm{rpm}$ for $10 \mathrm{~min}$. The supernatant was evaporated to dryness under reduced pressure (fraction A). The residue was extracted three times with $50 \mathrm{ml}$ of chloroformmethanol $(2: 1, \mathrm{v} / \mathrm{v})$ for $60 \mathrm{~min}$ at $40^{\circ} \mathrm{C}$, and centrifuged at $3000 \mathrm{rpm}$ for $10 \mathrm{~min}$. The three combined extracts were evaporated to dryness under reduced pressure (fraction $\mathrm{C}$ ), The residue was suspended in $50 \mathrm{ml}$ of $5 \%$ trichloroacetic acid (TCA) and then the suspension was stirred at $30^{\circ} \mathrm{C}$ for $30 \mathrm{~min}$. The suspension was then centrifuged for $10 \mathrm{~min}$ at $3000 \mathrm{rpm}$. The precipitate was re-extracted twice under the same conditions. The combined supernatant was evaporated to dryness under reduced pressure (fraction C), and the precipitate was refluxed twice in $50 \mathrm{ml}$ of $5 \%$ TCA for $15 \mathrm{~min}$ and then centrifuged for $10 \mathrm{~min}$ at $4000 \mathrm{rpm}$. The supernatant was evaporated to dryness under reduced pressure (fraction $\mathrm{D}$ ), and then the precipitate (fraction $\mathrm{E}$ ) was washed with $30 \mathrm{ml}$ of ether, ethanol and hot ethanol, successively.

A portion of each fraction was hydrolyzed with $10 \mathrm{ml}$ of $6 \mathrm{~N} \mathrm{HCl}$ at $120^{\circ} \mathrm{C}$ for $24 \mathrm{hr}$. Water was added to the hydrolysate, and then the mixture was extracted several times with ether. The aqueous layer was filtered, evapo- rated to dryness and then redissolved with $10 \mathrm{ml}$ of water for analysis of phosphonate- and total-phosphorus.

Preparation of lipid extracts. The freeze-dried material $(5 \mathrm{~g})$ of AGEMAKI, Sinonovacula constricta, was extracted with $50 \mathrm{ml}$ of chloroform-methanol $(2: 1, \mathrm{v} / \mathrm{v})$ at $40^{\circ} \mathrm{C}$ for $60 \mathrm{~min}$, and then the insoluble residue was reextracted twice under the same conditions. The three combined extracts were evaporated to dryness under reduced pressure, redissolved in $10 \mathrm{ml}$ of chloroformmethanol $(2: 1, \mathrm{v} / \mathrm{v})$ and then washed twice with $70 \mathrm{ml}$ of cold acetone. The precipitate was collected by centrifugation at $3000 \mathrm{rpm}$ for $10 \mathrm{~min}$, redissolved in $10 \mathrm{ml}$ of chloroform-methanol $(2: 1, \mathrm{v} / \mathrm{v})$ and then washed three times with a 0.2 volume of $0.017 \% \mathrm{MgCl}_{2}$, according to the method described by Folch et al. ${ }^{15)}$ The lower phase was evaporated to dryness under reduced pressure. The isolation and purification of the sphingolipid from the total lipid was achieved by three methods; by mild alkaline hydrolysis according to Dawson ${ }^{16)}$ and Hori et al. ${ }^{17)}$, by QAE-Sephadex column chromatography and by preparative thin layer chromatography.

Mild alkaline hydrolysis. To a solution of the lipid in $10 \mathrm{ml}$ of chloroform-methanol $(2: 1, \mathrm{v} / \mathrm{v}), 10 \mathrm{ml}$ of $0.5 \mathrm{~N}$ methanolic sodium hydroxide was added.

The mixture was stirred at $37^{\circ} \mathrm{C}$ for $60 \mathrm{~min}$ and then adjusted with $2.6 \mathrm{~N}$ methanolic hydrochloride to $\mathrm{pH} 1$. The mixture was then kept at $37^{\circ} \mathrm{C}$ for $60 \mathrm{~min}$. The methanol was removed under reduced pressure, and then the residual solid was shaken with $1 \mathrm{ml}$ of water containing $0.27 \mathrm{~g}$ of sodium sulfate and later with $20 \mathrm{ml}$ of water. The lipid was extracted three times with $20 \mathrm{ml}$ of chloroform. After centrifugation, the three combined extracts were evaporated to dryness under reduced pressure. The residual solid was washed twice with cold acetone, and then the sphingolipid precipitate was collected by centrifugation at $3000 \mathrm{rpm}$ for $15 \mathrm{~min}$.

Fractionation by column chromatography. The dried sphingolipid residue was dissolved in a small amount of chloroform-methanol $(2: 1, \mathrm{v} / \mathrm{v})$ and then applied to a $1.2 \times 17 \mathrm{~cm}$ column of QAE-Sephadex A-25 (prewashed with chloroform-methanol-water $(2: 4: 1, \mathrm{v} / \mathrm{v}))$. The column was first eluted with $100 \mathrm{ml}$ of chloroformmethanol-water $(2: 4: 1, \mathrm{v} / \mathrm{v})$ and then with $500 \mathrm{ml}$ of chloroform-methanol- $1 \mathrm{M}$ sodium acetate $(2: 4: 1, \mathrm{v} / \mathrm{v})$. The eluate was collected in $1.4 \mathrm{ml}$ fractions and examined by thin layer chromatography on Kiesel gel $60 \mathrm{~F}_{254}$ (Merck, $0.25 \mathrm{~mm}, 20 \times 20 \mathrm{~cm}$ ) with chloroform-methanol- $28 \%$ aqueous ammonia $(65: 35: 5, \mathrm{v} / \mathrm{v})$. The spots were detected with $\mathrm{I}_{2}$ vapor and ninhydrine.

Fraction No.86 of the eluate was collected and evaporated to dryness under reduced pressure. The dried residue was dissolved in a small amount of chloroformmethanol- $1 \mathrm{~m}$ sodium acetate $(2: 4: 1, \mathrm{v} / \mathrm{v})$ and further applied to a $1.2 \times 17 \mathrm{~cm}$ column of QAE-Sephadex A-25 as 
described above. The column was eluted with $200 \mathrm{ml}$ of chloroform-methanol-1 $\mathrm{M}$ sodium acetate $(2: 4: 1, \mathrm{v} / \mathrm{v})$.

The eluate was collected in $1.4 \mathrm{ml}$ fractions and examined by thin layer chromatography as described above.

Fraction Nos. $7 \sim 9$ of the eluate were collected and evaporated to dryness under reduced pressure. As will be described below, this dried material $(134 \mathrm{mg})$ was used as crude phosphonolipids.

Isolation of ceramide aminoethylphosphonate by preparative thin layer chromatography. The dried residue was dissolved in $1 \mathrm{ml}$ of chloroform-methanol $(2: 1, \mathrm{v} / \mathrm{v})$ and then applied to 5 thin layer plates of Kiesel gel $60 \mathrm{~F}_{254}$ (Merck, $2 \mathrm{~mm}, 20 \times 20 \mathrm{~cm}$ ). Chromatography was carried out at $20^{\circ} \mathrm{C}$ with chloroform-methanol-acetic acidwater $(100: 20: 12: 5, \mathrm{v} / \mathrm{v})$. The spots were detected with $I_{2}$ vapor.

To isolate ceramide aminoethylphosphonate, the desired area of the thin layer plates was scraped off, and packed into a column $(1.0 \times 10 \mathrm{~cm})$, and then the material was eluted from the scraped Kiesel gel with chloroformmethanol-water $(10: 10: 1, \mathrm{v} / \mathrm{v})$.

The eluate was evaporated to dryness under reduced pressure and then crystallized by dissolving in ethyl acetate-methanol $(3: 2)$.

Infrared analysis. The infrared absorption spectrum was determined on a pellet of potassium bromide with a Nihonbunko IR-S Spectrophotometer.

Qualitative analysis. The ceramide aminoethylphosphonate was hydrolyzed with $6 \mathrm{~N} \mathrm{HCl}$ at $120^{\circ} \mathrm{C}$ for $24 \mathrm{hr}$. The liberated fatty acids were extracted with light petroleum and then the water soluble compounds were extracted by means of Folch partition. The aqueous phase was evaporated to dryness under reduced pressure.

The presence of aminoethylphosphonate in the acid hydrolysate was demonstrated by thin layer chromatography (Kiesel gel $60 \mathrm{~F}_{254}, 20 \times 20 \mathrm{~cm}, 0.25 \mathrm{~mm}$ ) with $99 \%$ ethanol-7\% aqueous ammonia $(1: 2, \mathrm{v} / \mathrm{v}) .^{13,18)}$

Authentic 2-aminoethylphosphonic acid prepared by the method of Kosolapoff ${ }^{19}$ ) was co-chromatographed, and the spots were detected by Resenberg's method. ${ }^{20)}$

Quantitative analysis. Fatty acid esters were obtained from the ceramide aminoethylphosphonate by means of methanolysis $\left(5 \% \mathrm{HCl}\right.$ in methanol at $100^{\circ} \mathrm{C}$ for $\left.4 \mathrm{hr}\right)$ and then subjected to gas chromatography. The sphingosine content of the sample was determined by the method of Lauter et al., ${ }^{21)}$ which depends on the colorimetric estimation of the complex formed between sphingosine and methyl orange. Phosphonate phosphorus was estimated by the method of Tamari et al. ${ }^{22}$ Total phosphorus was estimated by the method of Chen et al. ${ }^{23)}$ Analysis of carbon, hydrogen and nitrogen was carried out with a Perkin-Elmer 240 Microanalysis Apparatus.
Gas liquid chromatographic analysis of the fatty acid composition. The fatty acid methyl esters were separated with a Shimadzu GC-9A apparatus equipped with a flame ionization detector.

The column was a $3 \mathrm{~mm} \times 2 \mathrm{~m}$ glass column packed with $5 \%$ Shinchron E71 on $80 \sim 100$ mesh Chimalite, and the instrument was operated at $200^{\circ} \mathrm{C}$. The peaks were identified by comparison with those of standard methyl esters on the basis of individual retention times.

\section{RESULTS}

The amounts of phosphonate in the acetone, lipid, cold and hot TCA soluble and protein fractions of AGEMAKI, Sinonovacula constricta, were $3.25,164.60,41.35,68.46$ and $35.37 \mu \mathrm{g}$ per $\mathrm{g}$ of freeze-dried sample, respectively. The lipid fraction contained $52.5 \%$ of the phosphonate in the Sinonovacula constricta powder, and the amount of phosphonate in the lipid fraction was 3.9, 2.4 and 4.6 times higher than those in the cold TCA, in the hot TCA and in the protein fractions, respectively.

Lipid extraction yielded $1.1 \mathrm{~g}$ of purified total lipids $(11.0 \%$ of the dry weight). The phospholipid content of the total lipid was about $14.6 \%$ by wt. The phosphorus content of the total phospholipid amounted to $3.9 \%$. About $28 \%$ of the total phosphorus was found to be phosphonate, which was identified as 2aminoethylphosphonic acid.

A typical thin layer chromatographic separation of the phospholipid classes is depicted in Fig. 1, while the quantitative phospholipid distribution determined by phosphorus analysis of the spots shown in Fig. 2 is presented in Table I. With minor exceptions, the polar lipid composition of Sinonovacula constricta was identical to that of other invertebrates..$^{24}$ 29)

Phosphatidylethanolamine (spot 1, 25.5\%) appears to be present in large amounts together with small amounts of phosphatidylcholine (spot 2, 9.5\%) and phosphatidylserine (spot 4, 8.0\%). Ceramide aminoethylphosphonate (spot 3 ) comprised $23.1 \%$ of the lipid phosphorus. The phosphonate analog of the phosphatidylethanolamine was not detected in the phospholipid of Sinonovacula constricta. 


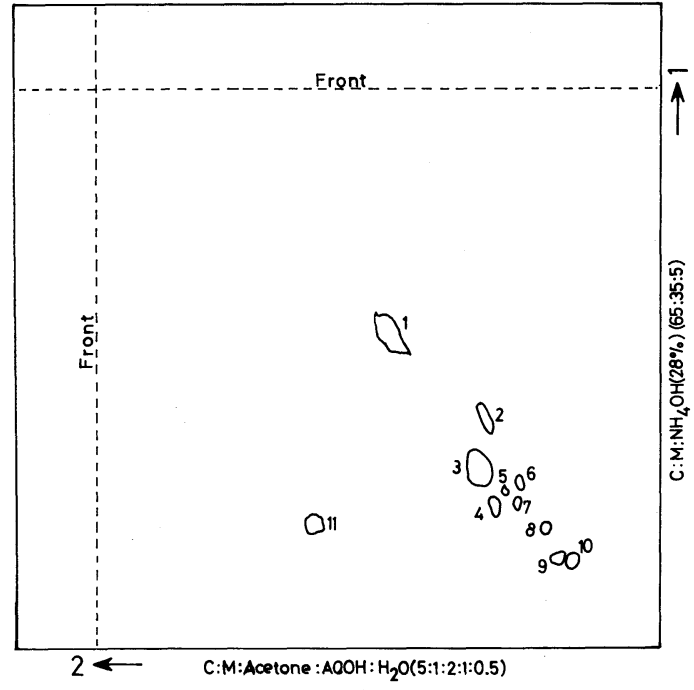

Frg. 1. Two Dimensional Thin Layer Chromatogram of the Phospholipids of Sinonovacula constricta.

The chromatogram was developed in chloroformmethanol-28\% aqueous ammonia $(65: 35: 5, \mathrm{v} / \mathrm{v})$ in the upper direction, then chloroform-methanol-acetoneacetic acid-water $(5: 1: 2: 1: 0.5, \mathrm{v} / \mathrm{v})$ toward the left. Spot are: 1 , phosphatidylethanolamine; 2 , phosphatidylcholine; 3, ceramide aminoethylphosphonate; 4, phosphatidylserine; 5, phosphatidylinositol; $6 \sim 10$, unidentified lipids; 11, phosphatidic acid.

TABle I. Phospholipid Composition of AGEMAKI, Sinonovacula constricta

\begin{tabular}{lc}
\hline \multicolumn{1}{c}{ Phospholipid class } & Percentage \\
\hline Phosphatidylethanolamine & 25.4 \\
Phosphatidylcholine & 9.5 \\
Ceramide aminoethylphosphonate & 23.1 \\
Phosphatidylserine & 8.0 \\
Phosphatidylinositol & 3.0 \\
Unidentified lipid & 20.2 \\
Phosphatidic acid & 10.8 \\
\hline
\end{tabular}

Figure 2 shows a thin layer chromatogram of the lipid obtained by the mild alkaline hydrolysis method.

Ceramide aminoethylphosphonate (spot 1), hydroxy fatty acid containing ceramide aminoethylphosphonate (spot 2) and sphingomyelin (spot 3) consisted of 75.8, 12.3 and $11.9 \%$ of the sphingolipid phosphorus, respectively.

The results obtained here indicate that

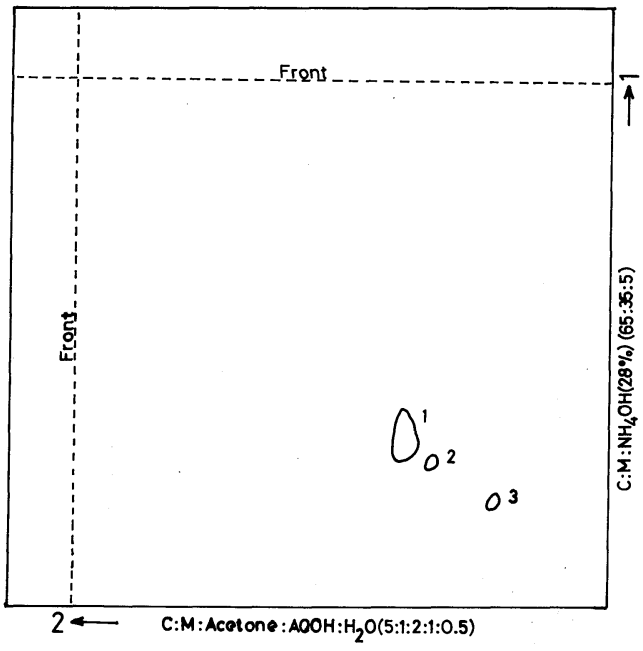

FIG. 2. Two Dimensional Thin Layer Chromatogram of the Alkaline Stable Lipids Obtained by the Mild Alkaline Hydrolysis as Described in the Text.

The chromatogram was developed as in Fig. 1. Spot are: 1, ceramide aminoethylphosphonate $(75.8 \%) ; 2$, probably hydroxy fatty acid containing ceramide aminoethylphosphonate $(12.3 \%)$; 3, sphingomyelin $(11.9 \%)$.

ceramide aminoethylphosphonate is the major sphingolipid component of the lipid moiety of Sinonovacula constricta.

$18 \mathrm{mg}$ of ceramide aminoethylphosphonate was finally obtained from the sphingolipid $(0.1 \mathrm{~g})$ of Sinonovacula constricta $(5 \mathrm{~g}$ dry weight).

Figure 3 shows the infrared spectrum of the ceramide aminoethylphosphonate obtained by the alkaline hydrolysis method. The infrared spectrum lacked a band at $1730 \sim 1750 \mathrm{~cm}^{-1}$, indicating the absence of ester bonds. A band was present at $1180 \mathrm{~cm}^{-1}$, indicating the presence of a carbon-phosphorus bond, and the spectrum was essentially identical with that of ceramide aminoethylphosphonate, as obtained by Rouser et al. ${ }^{11)}$, Hayashi et al. ${ }^{30)}$ and Hori et al. ${ }^{16,31)}$

Figure 4 shows a thin layer chromatogram of the carbon-phosphorus compound in the acid hydrolysate of the ceramide aminoethylphosphonate from Sinonovacula constricta.

The carbon-phosphorus compound in the hydrolysate of the ceramide aminoethylphosphonate obtained by acid hydrolysis as de- 


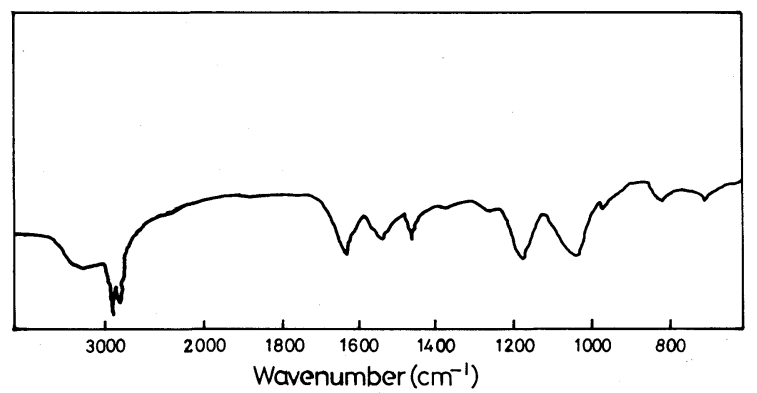

FIG. 3. Infrared Spectrum of the Ceramide Aminoethylphosphonate Purified by a Combination of the Mild Alkaline Hydrolysis, the Column Chromatography and the Preparative Thin Layer Chromatography as Described in the Text.

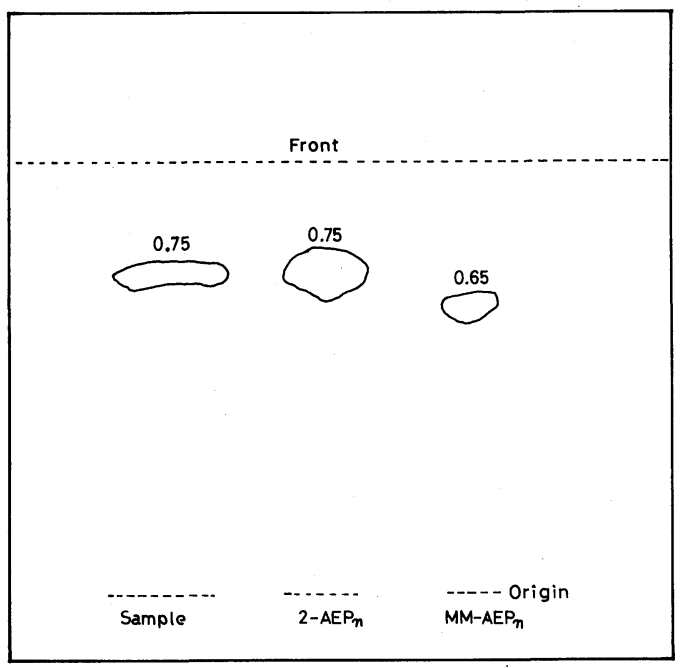

FIG. 4. Chromatographic Identification of the Aminophosphonates in the Acid Hydrolysate of the Ceramide Aminoethylphosphonate.

Authentic 2-aminoethylphosphonic acid (2-AEP), $N$ mono-methylaminoethylphosphonic acid (MM-AEP) and the acid hydrolysate were spotted at the origin. Chromatography was carried out on a Kiesel gel $60 \mathrm{~F}_{254}$ plate with $99 \%$ ethanol $-7 \%$ aqueous ammonia $(1: 2$, $\mathrm{v} / \mathrm{v}) .{ }^{17)}$ The spots were detected with ninhydrine and Rosenberg's reagent. ${ }^{20}$ )

scribed earlier in the text were found to be 2aminoethylphosphonic acid by thin layer chromatography.

The $R f(0.75)$ of the spot agreed with that of authentic 2-aminoethylphosphonic acid synthesized by Kosolapoff's method. ${ }^{19)}$ Inorganic phosphorus and $\mathrm{N}$-methyl derivatives of 2aminoethylphosphonic acid were not detected in the hydrolysate.
Table II. Analytical Data for the Ceramide Aminoethylphosphonate Purified by Mild Alkaline Hydrolysis from AGEMAKI, Sinonovacula constricta

\begin{tabular}{lrc}
\hline & Found & $\begin{array}{c}\text { Calcd. for } \\
\mathrm{C}_{37} \mathrm{H}_{75} \mathrm{O}_{5} \mathrm{~N}_{2} \mathrm{P}\end{array}$ \\
\hline $\mathrm{N}$ & 4.21 & 4.25 \\
Amino N & 1.91 & 2.13 \\
Long chain base $\mathrm{N}$ & 1.86 & 2.13 \\
Sphingosine & 41.20 & 45.40 \\
$\mathrm{P}$ & 4.62 & 4.70 \\
$\mathrm{~N}: \mathrm{P}$ (molar ratio) & 2.02 & 2.00 \\
$\mathrm{C}$ & 66.72 & 67.43 \\
$\mathrm{H}$ & 11.31 & 11.48 \\
Fatty acid & 40.20 & 41.10 \\
\hline
\end{tabular}

Table II shows the chemical data for the ceramide aminoethylphosphonate isolated from the Sinonovacula constricta.

As shown in the table, the analytical values estimated for the ceramide aminoethylphophonate agreed closely with the calculated values, except for sphingosine as well as longchain base-N. Moverover, there is not a gross difference except for sphingosine between the present results and those by the method which had been previously reported by Hori et al. ${ }^{31)}$

The results of gas chromatographic analysis of the fatty acid composition are shown in Table III. The fatty acid composition was very simple. The fatty acid composition of the ceramide aminoethylphosphonate was characterized by the relatively high percentages of palmitic acid and stearic acid, which 
TABle III. Fatty ACID Composition of the Ceramide Aminoethylphosphonate from AGEMAKI, Sinonovacula constricta

\begin{tabular}{lr}
\hline \multicolumn{1}{c}{ Fatty acid } & $\%$ \\
\hline Lauric acid & 0.30 \\
Myristic acid & 0.96 \\
Pentadecanoic acid & 2.09 \\
Palmitic acid & 59.98 \\
Margaric acid & 8.58 \\
Stearic acid & 20.29 \\
Linoleic acid. & 0.03 \\
Linolenic acid & 0.24 \\
Arachidic acid & 2.28 \\
Eicosapentaenoic acid & 0.61 \\
Behenic acid & 0.43 \\
Unknown & 4.22 \\
\hline Average carbon number & 17.3 \\
\hline
\end{tabular}

conforms to fatty acid composition of the ceramide aminoethylphosphonate in other invertebrates. ${ }^{24 \sim 28}$ ) The sum of these two acids comprised about $80 \%$ of the total fatty acids. Pentadecanoic acid $(2.1 \%)$, margaric acid $(8.6 \%)$ and arachidic acid $(2.3 \%)$ were also found as minor components.

From the above results, the isolated phosphonolipid was identified as ceramide 2aminoethylphosphonate.

\section{DISCUSSION}

The distribution of phosphonolipids in nature is primarily limited to lower animals such as molluscs, coelenterates and protozoa, although such lipids have also been found in small quantities in mammalian tissues. ${ }^{32 ~ 34)}$

In the phosphonolipids, it has been established that glycero-aminoethylphosphonate (GPnL) occurs as the major phospholipid of the ciliary membrane of protozoan species. ${ }^{35,36)}$

To date, there is no report yet on the detection of the GPnL in shellfish and sea anemones.

On the other hand, ceramide aminoethylphosphonate consists of 2-aminoethylphosphonic acid substituted on the primary hydroxyl group of a characteristic sphingosine base.

Ceramide aminoethylphosphonate is found in high concentrations in molluscs, coelenterates and shellfish such as $T$. Cornutus, Monodonta labio and Tegula liochkei, while the concentration is low in Tetrahymena.

Matsubara $^{37)}$ found that the oyster adductor muscle contained the highest concentration (45\% of the total sphingolipids) of ceramide aminoethylphosphonate. Komai et al. ${ }^{38)}$ found that ceramide aminoethylphosphonate occurs in approximately $11 \%$ of the phospholipids in the nervous system of $A$. Kurodai, a marine gastropod. Moreover, Komai et al. speculated that ceramide aminoethylphosphonate may be indispensable in shellfish for the neuronal function.

Matsubara ${ }^{39)}$ and Itasaka et al. $^{40)}$ reported that ceramide aminoethylphosphonate and ceramide monomethylaminoethylphosphonate occur in some shellfish and that the concentration ratio of the former and the latter were $89: 11$ in Sinotoia histria, 68:32 in Semisulcospira bensoni, 69:31 in M. labis and $85: 15$ in the land snail, Helix pomatia.

While this sphingolipid is unique to invertebrates, its exact function is unknown, but their resistance to endogenous hydrolytic enzymes is highly suggestive of a protective function. Kittredge et al. ${ }^{41)}$ indicate that the presence of a covalent carbon-phosphorus linkage in the anemone has been postulated as functionally analogous to a fixation process.

Mason $^{29)}$ indicates the possibility that the presence of a highly ionic lipid such as ceramide aminoethylphosphonate could play a direct role in facilitating the transport of small ions from the aqueous environment into the intercellular space of the anemone.

On the other hand, the occurrence of 2aminoethylphosphonic acid in human tissues has been reported. ${ }^{24)}$

These results suggest that 2-aminoethylphosphonic acid originating from marine products may be found in may human tissues, and that a person could ingest this compound through fishery products as well 
as dairy products. ${ }^{43)}$

Acknowledgments. The authors wish to express their thanks to Professor Dr. M. Horiguchi of Tohoku University for his many valuable comments and to Dr. $\mathrm{H}$. Sakaguchi of the Faculty of Fisheries of Nagasaki University for recording the fatty acids analyses.

Thanks are also due to instructor Ronald Gosewish of Nagasaki University for his revisions of the manuscript.

\section{REFERENCES}

1) M. Horiguchi and M. Kandatsu, Nature (London), 184, 901 (1959).

2) L. D. Quin, "In Topics in Phosphorus Chemistry," Vol. 4, ed. by M. Grayson and E. J. Griffith, Interscience, New York, 1966, p. 23.

3) T. Hori, I. Arakawa and M. Sugita, J. Biochem., 62, 67 (1967).

4) M. Tamari, Nippon Nôgeikagaku Kaishi, 51, R131 (1977).

5) J. S. Kittredge and R. R. Hughes, Biochemistry, 3, 991 (1964).

6) J. S. Kittredge, A. F. Isbell and R. R. Hughes, Biochemistry, 6, 289 (1967).

7) E. Baer and N. Z. Stanacov, J. Biol. Chem., 239, 3209 (1965).

8) J. S. Kittredge and E. Robert, Science, 164, 37 (1969).

9) S. Hasegawa, M. Tamari and M. Kametaka, $J$. Biochem., 80, 531 (1976).

10) H. Rosenberg, Nature, 203, 229 (1964).

11) G. Rouser, D. H. Kitchevsky, D. Heller and E. Lieber, J. Am. Oil Chemists Soc., 40, 425 (1963).

12) T. Hori, O. Itasaka and H. Inoue, J. Biochem., 56, 477 (1964).

13) M. K. Wassef and J. W. Hendrix, Biochim. Biophys. Acta, 486, 172 (1977).

14) W. C. Schneider, J. Biol. Chem., 164, 747 (1946).

15) J. Folch, M. Lee and G. H. Sloan-Stanley, J. Biol. Chem., 226, 497 (1957).

16) R. M. C. Dawson, Biochemical J., 75, 45 (1960).

17) T. Hori, M. Sugita and O. Itasaka, J. Biochem., 65, 451 (1969).

18) J. A. Brushaber, J. J. Child and R. H. Haskins, Can. J. Microbiol., 18, 1059 (1972).
19) G. M. Kosolapoff, J. Am. Chem. Soc., 69, 2112 (1947).

20) H. Rosenberg, J. Chromatogr., 2, 487 (1959).

21) C. J. Lauter and.E. G. Trams, J. Lipid Res., 3, 136 (1962).

22) M. Tamari, M. Hóriguchi and M. Kandatsu, Nippon Nôgeikagaku Kaishi, 45, 433 (1971).

23) P. S. Chen, T. Y. Toribara and H. Warner, Anal. Chem., 28, 1756 (1956).

24) S. Higashi and T. Hori, Biochim. Biophys. Acta, 152, 568 (1968).

25) G. Simon and G. Rouser, Lipids, 2, 55 (1967).

26) A. J. De Koning, J. Sci. Fd. Agric., 17, 460 (1966).

27) T. Hori, O. Itasaka, T. Hashimoto and H. Inoue, $J$. Biochem. (Tokyo), 55, 545 (1964).

28) D. J. Van Der Horst, F. J. Kingma and R. C. H. M. Oudejans, Lipids, 8, 759 (1973).

29) W. T. Mason, Biochim. Biophys. Acta, 280, 538 (1972).

30) A. Hayashi, T. Matsubara and Y. Mishima, J. Fac. Sci. Tech. Kinki Univ., 2, 39 (1967).

31) T. Hori, O. Itasaka and H. Inoue, J. Biochem., 59, 570 (1966).

32) M. Tamari, M. Ogawa, S. Hasegawa and M. Kametaka, Agric. Biol. Chem., 40, 2057 (1976).

33) S. Hasegawa, M. Tamari and M. Kametaka, $J$. Biochem., 80, 531 (1976).

34) M. C. Moschidis, J. Chromatogr., 268, 485 (1983).

35) Y. Nozawa and G. A. Thompson, J. Cell Biol., 49, 712 (1971).

36) K. E. Kennedy and G. A. Thompson, Science, 168, 989 (1970).

37) T. Matsubara, Biochim. Biophys. Acta, 388, 353 (1975).

38) Y. Komai, S. Matsukawa and M. Satake, Biochim. Biophys. Acta, 316, 271 (1973).

39) T. Matsubara, Chem. Phys. Lipids, 14, 247 (1975).

40) O. Itasaka and T. Hori, Proc. Jap. Conf. Biochem. Lipids, 21, 62 (1979).

41) J. Kittredge, E. Roberts and D. Simonsen, Biochemistry, 1, 624 (1962).

42) J. A. Alhadeff and G. D. Daves, Biochemistry, 9, 4866 (1970).

43) M. Kandatsu and M. Horiguchi, Agric. Biol. Chem., 29, 781 (1965). 